\title{
Hydrothermal Synthesis of $\beta$-NaYF 4 :Yb, Er Nanocrystals with Upconversion Fluorescence Using Tetraethylene Pentamine as Chelating Ligand
}

\author{
Suli Wu, Yanhui Ning, and Shufen Zhang \\ State Key Laboratory of Fine Chemicals, Dalian University of Technology, Dalian 116024, China \\ Correspondence should be addressed to SuliWu,wusuli@dlut.edu.cn
}

Received 1 December 2011; Accepted 20 December 2011

Academic Editor: S. K. Rout

Copyright (C) 2012 Suli Wu et al. This is an open access article distributed under the Creative Commons Attribution License, which permits unrestricted use, distribution, and reproduction in any medium, provided the original work is properly cited.

\begin{abstract}
Novel chelating ligands are very significant for preparing nanocrystals with different morphologies and applications. In this paper, we directly introduced amine groups onto UCNPs by choosing a new chelating ligand tetraethylene pentamine (TEPA) to synthesis $\mathrm{NaYF}_{4}: \mathrm{Yb}$, Er through hydrothermal method. The influences of rare earth concentration, the ratio of RE/TEPA, solvent composition, and reaction time on the morphology and fluorescence intensity of the as-prepared $\mathrm{NaYF}_{4}: \mathrm{Yb}, \mathrm{Er}_{\mathrm{samples}}$ were systematically investigated and discussed. Field emission scanning electron microscopy (FE-SEM), powder X-ray diffraction (XRD), and upconversion luminescence spectroscopy were used to characterize the product. It was found that rare earth concentration, ratio of RE/TEPA, solvent composition, and reaction time were all responsible for the luminescent intensity and morphology.
\end{abstract}

\section{Introduction}

Upconversion (UC) means that the materials absorb longwaved photons to emit short-waved photons. Rare earth compounds have evoked much attention due to their novel electronic, optical, and chemical characteristics. The special $4 \mathrm{f}$ shell electron structure of the rare earth elements makes the upconverting nanoparticles (UCNPs) capable of converting two or more near-infrared (NIR) photons to one visible light photon via continuing electronic excitation and energy transfer processes [1]. Compared with downconversion materials quantum dots (QD), UCNPs have low toxicity to body, minimal autofluorescence, sharp absorption, and long life time [2]. These properties make them have great applications in various fields, such as biological labeling [3], illuminations [4], solar cells [5], optical storage [6], lightemitting diodes [7], drug-delivery [8], and photodynamic therapy [9]. NIR light with strong penetration ability has less harmful to cells and is safe for our bodies, so the applications of UCNPs on medicine and biological are especially important and have very bright prospects. As we know, $\mathrm{NaYF}_{4}$ is the best host material for UCNPs due to the low lattice phonon energy and good thermal stability, and $\mathrm{NaYF}_{4}$ doped with $\mathrm{Yb}$, Er is frequently used as highly efficient upconversion materials.

Generally, the synthesis methods of UCNPs can be divided into two categories. One was thermolysis method, using long chain organic ligands as solvent and chelating ligand under very high temperature $\left(300-340^{\circ} \mathrm{C}\right)$. Because of the high temperature of the thermolysis synthesis, few chelating ligands can be choosen. The most frequently used chelating ligand was oleic acid (OA) together with a noncoordinating solvent octadecene (ODE), which controlled the nucleation and growth as well as stabilization of the crystals in a thermolysis procedure. Other chelating ligands such as oleylamine [10], octadecylamine [11], oleamide [12], trioctylphosphine (TOP) [13], and trioctylphosphine oxide (TOPO) were also used to prepare $\mathrm{NaYF}_{4}: \mathrm{Yb}, \mathrm{Er}$ [14]. All these are high boiling point solvent, but the kinds of them are limited. The other method was hydro (solvent) thermal method. In this method, the reaction condition was relatively mild (heating temperature was generally $140-240^{\circ} \mathrm{C}$ ), so some low boiling point ligands can be applied. However, few chelating ligands have reported to guide the crystal's growth 
and control the morphology of the nanoparticles. Sodium citrate [15], ethylenediamine tetraacetate (EDTA) [16], and oleic acid (OA) [17] were most people's choices, the coordination groups of them are all carbonyl group with good coordination ability, and the shapes of $\mathrm{NaYF}_{4}: \mathrm{Yb}$, Er were mainly rod, prism, plate, and sphere. Using novel chelating ligands are very significant for preparing nanocrystals with different morphologies and applications. For example, in order to use UCNPs for bioprobe and bioimaging, some researchers used amine group to replace the other chelating ligands for biocompatibility by surface modification [18].

Herein, we directly introduced amine groups onto UCNPs by choosing a new chelating ligand tetraethylene pentamine (TEPA) to synthesis $\mathrm{NaYF}_{4}: \mathrm{Yb}$, Er through hydrothermal method. Tetraethylene pentamine's coordination groups are amine whose coordination ability is relatively week, while rod $\beta-\mathrm{NaYF}_{4}: \mathrm{Yb}$, Er nanoparticle can also be achieved. The exist of several amino of tetraethylene pentamine (TEPA) not only has a role of coordination but also can act as active point. We can introduce amine to the $\beta-\mathrm{NaYF}_{4}: \mathrm{Yb}$, Er nanocrystals directly without any other steps. Through amine, we can also introduce other functional groups, controlling the application performance of the $\beta$ $\mathrm{NaYF}_{4}: \mathrm{Yb}$, Er nanocrystals.

\section{Experimental}

2.1. Chemicals. All the chemicals were used directly without further purification. Tetraethylene pentamine (chemical grade) and $\mathrm{Y}\left(\mathrm{NO}_{3}\right)_{3} \cdot 6 \mathrm{H}_{2} \mathrm{O}(99.0 \%)$ were purchased from Sinopharm Chemicals Reagents Co., Ltd (Shanghai, China). $\mathrm{Yb}\left(\mathrm{NO}_{3}\right)_{3} \cdot 5 \mathrm{H}_{2} \mathrm{O}(99.99 \%), \mathrm{Er}\left(\mathrm{NO}_{3}\right)_{3} \cdot 5 \mathrm{H}_{2} \mathrm{O}(99.9 \%)$ were supplied by Aladdin Chemistry Co. Ltd. NaF was analytical grade and brought from Tianjing Kermel Chemical Reagents Development Center (Tianjing, China).

2.2. Synthesis of $\mathrm{NaYF}_{4}: \mathrm{Yb}, \mathrm{Er} U C N P s$. In a typical synthesis of hexagonal phase $\mathrm{NaYF}_{4}: \mathrm{Yb}$, Er nanocrystals, $4 \mathrm{~mL} 0.25 \mathrm{M}$ $78 \% \mathrm{Y}\left(\mathrm{NO}_{3}\right)_{3}, 20 \% \mathrm{Yb}\left(\mathrm{NO}_{3}\right)_{3}, 2 \% \mathrm{Er}\left(\mathrm{NO}_{3}\right)_{3}$ aqueous solution, $16 \mathrm{~mL}$ deionized water, and $20 \mathrm{~mL}$ ethanol were mixed with stirring at room temperature, after then, $0.2 \mathrm{~mL}$ TEPA was added into above solution, forming a A solution. $504 \mathrm{mg}$ $\mathrm{NaF}$ was dissolved in $10 \mathrm{~mL}$ deionized water and $10 \mathrm{~mL}$ ethanol to form solution B. After $0.5 \mathrm{~h}$ stirring of solution A, B solution was added into A solution drop by drop under vigorous stirring. After aging for $30 \mathrm{~min}$, the mixture was transferred to a $76 \mathrm{~mL}$ Teflon-lined autoclave, sealed, and heated at $200^{\circ} \mathrm{C}$ for $6 \mathrm{~h}$. As the autoclave was cooled to room temperature naturally, collected the precipitates in the bottle, washed with ethanol and deionized water in sequence, gathered the products by centrifugation, then dried in air at $70^{\circ} \mathrm{C}$ for $10 \mathrm{~h}$.

\section{Characterizations}

X-ray powder diffraction patterns were measured on a Rigaku D/MAX-2400 with Cu-Ka radiation. Upconversion fluorescence spectra were recorded on Hitachi F-4500 fluorescence spectrophotometer under the excitation of a $980 \mathrm{~nm}$

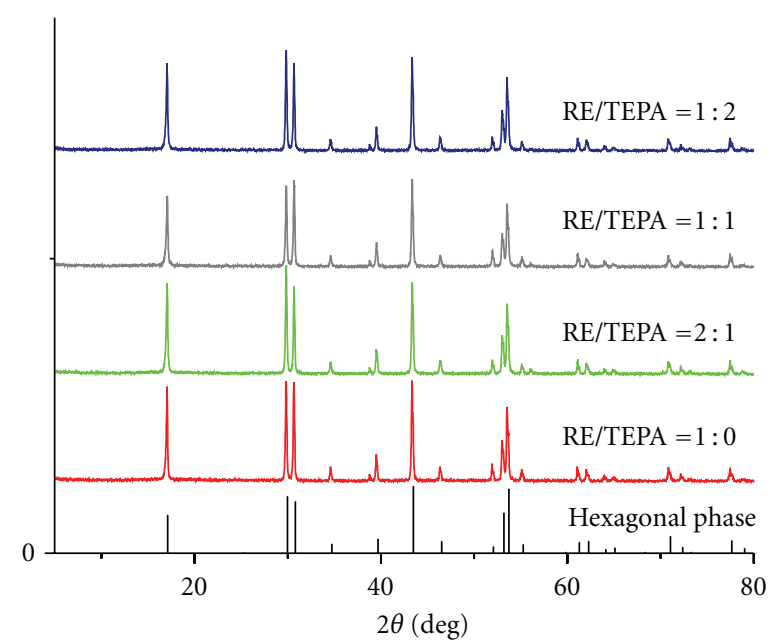

FIGURE 1: XRD patterns of $\mathrm{NaYF}_{4}: \mathrm{Yb}$, Er nanocrystals prepared under different ratio of RE/TEPA $(t=6 \mathrm{~h}$; water/ethanol $=1: 1$; $16.7 \mathrm{mmol} / \mathrm{L})$.

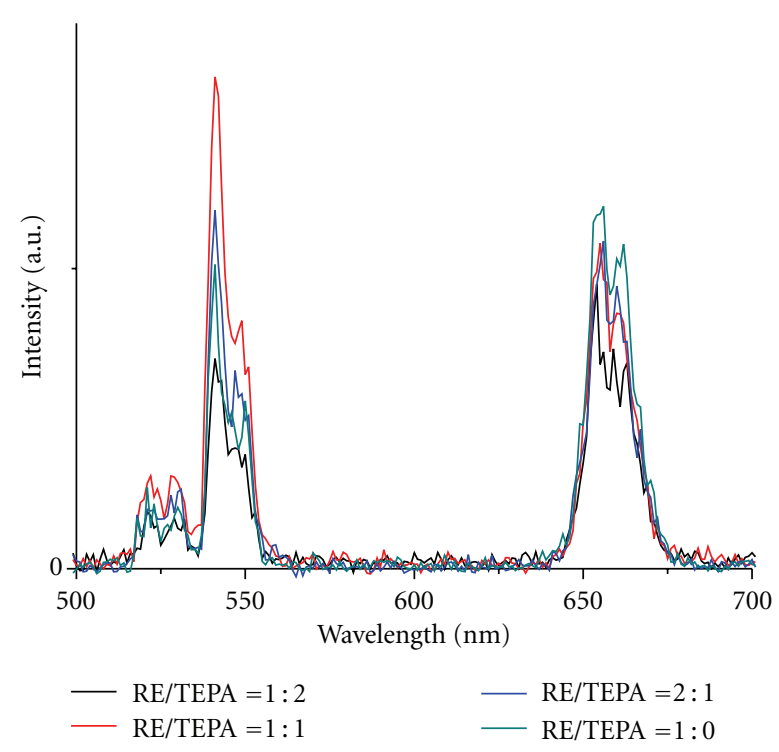

Figure 2: Upconverted fluorescence spectra of $\mathrm{NaYF}_{4}: \mathrm{Yb}, \mathrm{Er}$ nanocrystals prepared under different ratio of RE/TEPA $(t=6 \mathrm{~h}$; water/ethanol $=1: 1 ; 16.7 \mathrm{mmol} / \mathrm{L}$ ).

diode laser. The morphologies of the samples were observed by using a Nova Nanosem 450 field emission scanning electron microscopy (FE-SEM).

\section{Results and Discussion}

The synthetic conditions of $\mathrm{NaYF}_{4}: \mathrm{Yb}$, Er via the hydrothermal method were investigated in detail. The influences of rare earth concentration, solvent composition, the ratio of $\mathrm{RE} / \mathrm{TEPA}$, and reaction time were all found to have effect on the luminescence properties and morphology of $\mathrm{NaYF}_{4}: \mathrm{Yb}$, Er nanocrystals. 


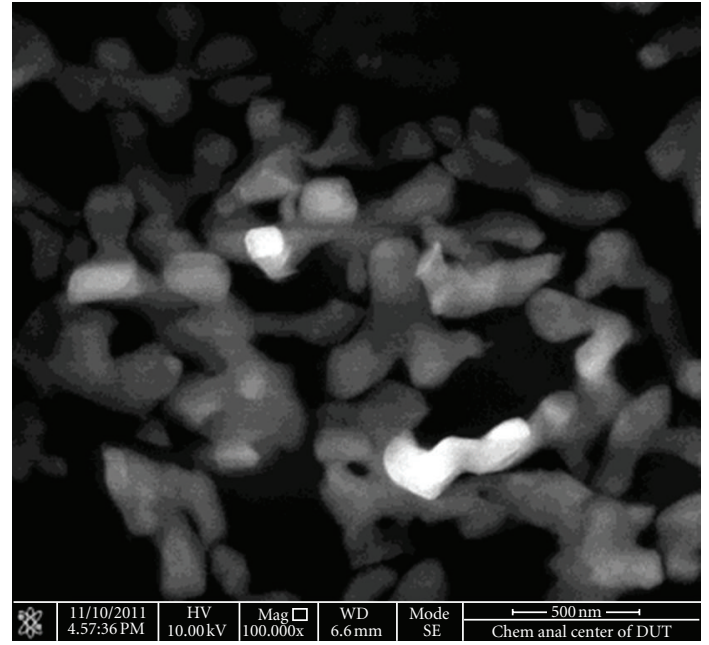

(a)

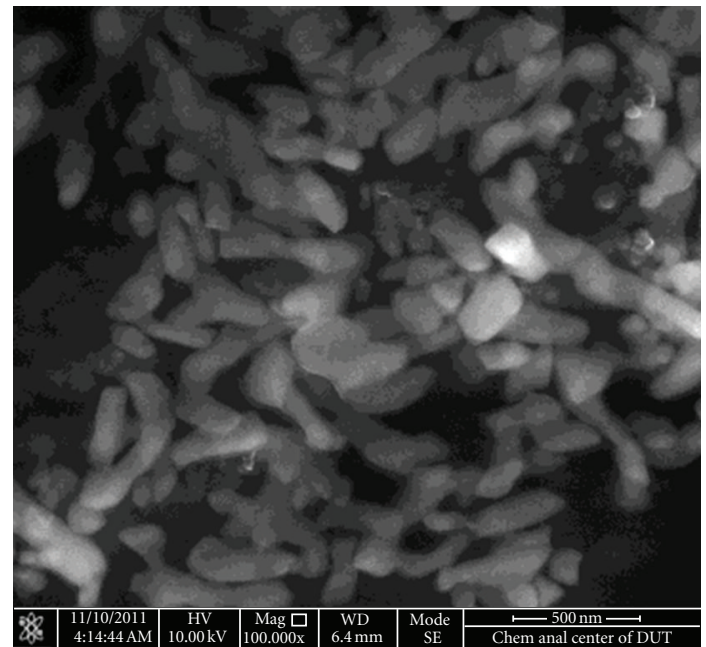

(c)

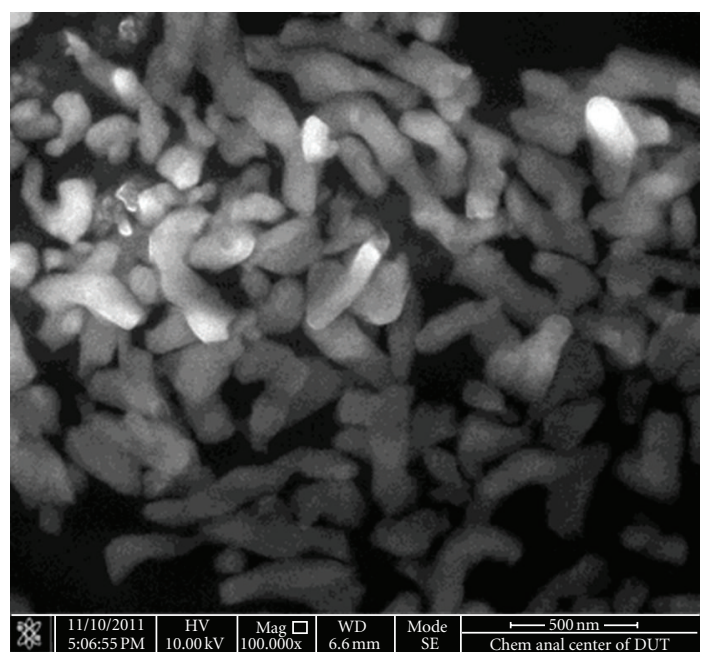

(b)

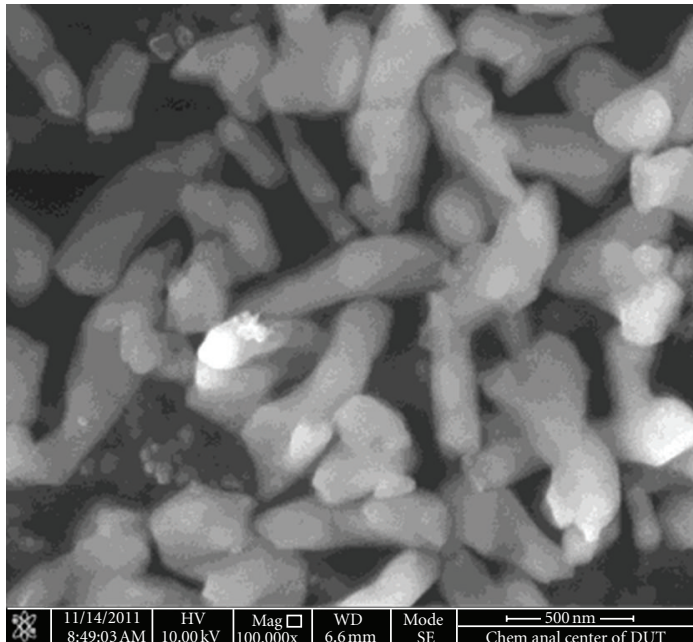

(d)

Figure 3: FE-SEM images of $\mathrm{NaYF}_{4}: \mathrm{Yb}$, Er nanocrystals prepared under different ratio of RE/TEPA: (a) RE/TEPA = 1:0; (b) RE/TEPA = $2: 1$; (c) RE/TEPA = $1: 1$; (d) RE/TEPA = $1: 2(t=6 \mathrm{~h}$; water $/$ ethanol $=1: 1 ; 16.7 \mathrm{mmol} / \mathrm{L})$.

4.1. Effect of the Ratio of RE/TEPA. It is know that chelating agent is very important to the crystal's growth and aggregation. To prove the effect of TEPA on $\mathrm{NaYF}_{4}: \mathrm{Yb}, \mathrm{Er}$ nanocrystals, $0 \mathrm{~mL}, 0.1 \mathrm{~mL}, 0.2 \mathrm{~mL}$, and $0.4 \mathrm{~mL}$ TEPA had been used to prepare $\mathrm{NaYF}_{4}: \mathrm{Yb}$, Er samples, that is, the ratio of the RE/TEPA was $1: 0,2: 1,1: 1$, and $1: 2$, respectively. Figure 1 shows the XRD spectra of the samples, and pure hexagonal $\mathrm{NaYF}_{4}$ phases are observed for all the samples. From the fluorescence spectra (Figure 2) of the as-prepared products, it can be seen that, when RE/TEPA $=1: 1$, the luminescent intensity of the product is strongest, while the fluorescence intensity is lowest when the ratio of RE to TEPA is $1: 2$. This may be due to the fact that excessive TEPA will lead to energy loss through high energy vibration [19]. FE-SEM of the samples are showed in Figure 3; under the condition of no chelators added, the morphology of the asprepared products was irregular. When TEPA is added, the morphology of the products became relative better. When the ratio of RE/TEPA is $2: 1 ; 1: 1$ and $1: 2$, the average size of the as-prepared nanocrystals are about $135 \mathrm{~nm}, 160 \mathrm{~nm}$, and $222 \mathrm{~nm}$, respectively. That is to say lower ratio of RE to TEPA is responsible for the larger particle size of $\beta-\mathrm{NaYF}_{4}: \mathrm{Yb}$, Er. Enough chelators could make more $\mathrm{RE}^{3+}$ coordinate with the $\mathrm{N}$ atom of TEPA and decrease the concentration of the $\mathrm{RE}^{3+}$ in the solvent; as a result, the speed of nucleation is delayed. As the time goes on, more and more rare earth ions are released and the crystals become bigger and bigger.

4.2. Effect of Reaction Time. Different reaction time was investigated to clarify that time has a effect on $\mathrm{NaYF}_{4}: \mathrm{Yb}$, Er nanocrystal's size and fluorescence intensity. $2 \mathrm{~h} ; 4 \mathrm{~h} ; 6 \mathrm{~h}$; $8 \mathrm{~h} ; 10 \mathrm{~h}$ were chosen to study. Figure 4 shows the XRD patterns of the samples, and it shows that all the samples are pure hexagonal; reaction time has little influence on 


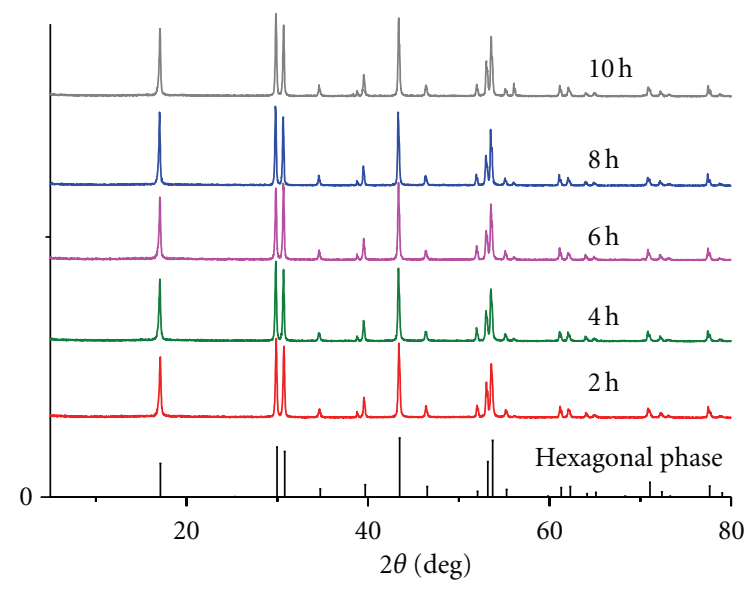

FIGURE 4: XRD patterns of $\mathrm{NaYF}_{4}: \mathrm{Yb}, \mathrm{Er}$ nanocrystals prepared under different reaction time $(\mathrm{RE} / \mathrm{TEPA}=1: 1$; water/ethanol $=$ $1: 1 ; 16.7 \mathrm{mmol} / \mathrm{L})$.

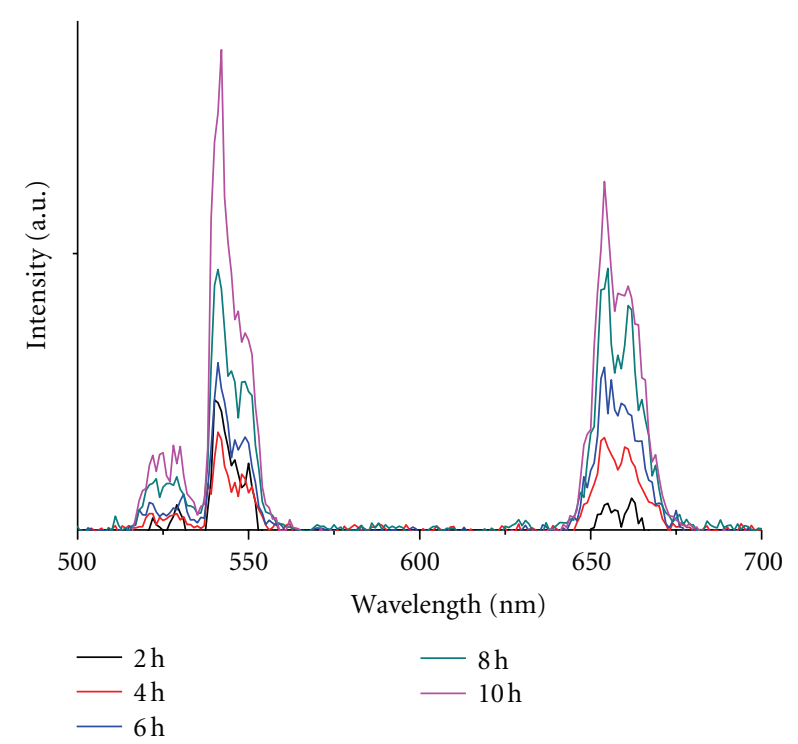

Figure 5: Upconverted fluorescence spectra of $\mathrm{NaYF}_{4}: \mathrm{Yb}, \mathrm{Er}$ nanocrystals prepared under different reaction time $(\mathrm{RE} / \mathrm{TEPA}=$ $1: 1 ;$ water/ethanol $=1: 1 ; 16.7 \mathrm{mmol} / \mathrm{L})$.

products' phase. Upconverted fluorescence spectra (Figure 5) show the difference between the as-prepared products; with the reaction time increases, the luminescent intensity of the nanoparticles was enhanced due to the increasing crystallinity. The FE-SEM of these samples (Figure 6) indicates when the reaction time is $2 \mathrm{~h}$, the size of the as-prepared samples is relatively small, increases the time to $4 \mathrm{~h}$, the size of the nanoparticles increases from $100 \mathrm{~nm}$ to $140 \mathrm{~nm}$, while when the reaction time extends from $6 \mathrm{~h}$ to $10 \mathrm{~h}$, the size of the nanoparticles has no evidence change.

4.3. Effect of Solvent Composition. Water and ethanol were used as solvent in this study. The composition of the water/ethanol was taken as $2: 1 ; 1: 1 ; 1: 2$ with identical other parameters. The XRD of the as-prepared products is showed in Figure 7; it clearly shows that all the samples are pure hexagonal phase. As in Figure 9, FE-SEM images show the morphology of the corresponding products, the size becomes smaller when the ratio of water to ethanol changes from $2: 1$ to $1: 2$, the average size of the corresponding samples is about $245 \mathrm{~nm} ; 160 \mathrm{~nm} ; 94 \mathrm{~nm}$. With the increase of ethanol in the solvent, the pressure of the autoclave increased and the solubility of the inorganic salts was lowered facilitating the supersaturation procedure, hence promoted the growth of the nanocrystal and improved the crystallinity of the nanocrystal [15]. Because the size of the sample prepared by water/ethanol $=1: 2$ is smaller than prepared by $1: 1$, considered both two factors, the luminescent intensity of the product prepared by water/ethanol $=1: 1$ was the strongest (Figure 8).

4.4. Effect of Rare Earth Concentration. As the volume of the Teflon-lined autoclave and total liquid is constant $(60 \mathrm{~mL})$, we changed moles of the rare earth to investigate the effect of the rare earth concentration on the fluorescence intensity and morphology of the as-prepared $\mathrm{NaYF}_{4}: \mathrm{Yb}$, Er. The concentration of the rare earth was taken as 8.33, 16.7, and $33.3 \mathrm{mmol} / \mathrm{L}$, respectively, the other parameters were constant. Figure 10 is the XRD patterns of these samples. It can be seen that all of the products are hexagonal phase, so the rare earth concentration has no effect on crystal phase. Figure 12 is the FE-SEM of the product; the average size of the prepared nanocrystals is about $182 \mathrm{~nm}, 160 \mathrm{~nm}$, and $125 \mathrm{~nm}$, respectively, when the rare earth concentration was $8.33,16.7$, and $33.3 \mathrm{mmol} / \mathrm{L}$. The lower the rare earth concentration is, the smaller the average size of the products. Rare earth concentration affects not only the morphology but also the fluorescence intensity of the prepared samples. The upconverted fluorescence spectra are given in Figure 11. When the rare earth concentration was $8.33 \mathrm{mmol} / \mathrm{L}$, the luminescence intensity was the highest. With the increasing of the rare earth concentration, the luminescence intensity reduced. The phenomenon may be due to the difference in size, the larger the size, the stronger the luminescence intensity.

\section{Conclusion}

In summary, we have directly introduced amine groups onto UCNPs using TEPA as a new chelating ligand. A series of hexagonal phase $\mathrm{NaYF}_{4}: \mathrm{Yb}$, Er nanoparticles was obtained through hydrothermal method. The influences of rare earth concentration, the ratio of rare earth to TEPA, reaction time, and solvent composition on the morphology and fluorescence intensity of the as-prepared $\mathrm{NaYF}_{4}: \mathrm{Yb}, \mathrm{Er}$ samples were investigated. It was found the lower the rare earth concentration, the stronger the fluorescence intensity of the as-prepared $\mathrm{NaYF}_{4}: \mathrm{Yb}$, Er. When the ratio of RE/TEPA decreased, the size of the as-prepared nanocrystals increased, while when RE/TEPA reduced to $1: 2$, the fluorescence intensity of the product decreased. Long reaction time was 


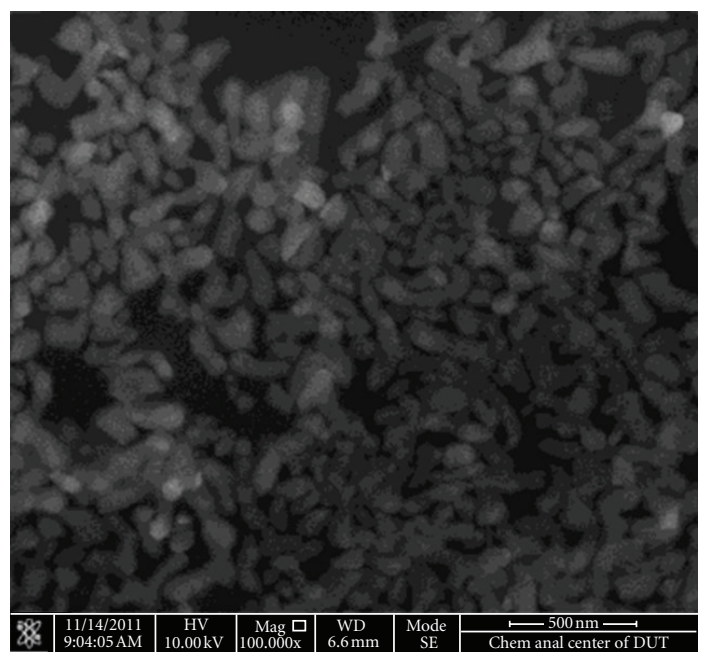

(a)

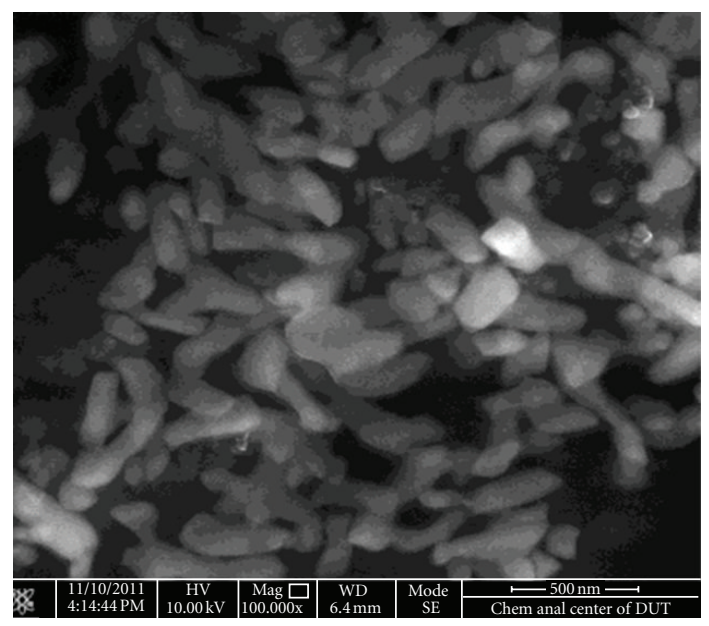

(c)

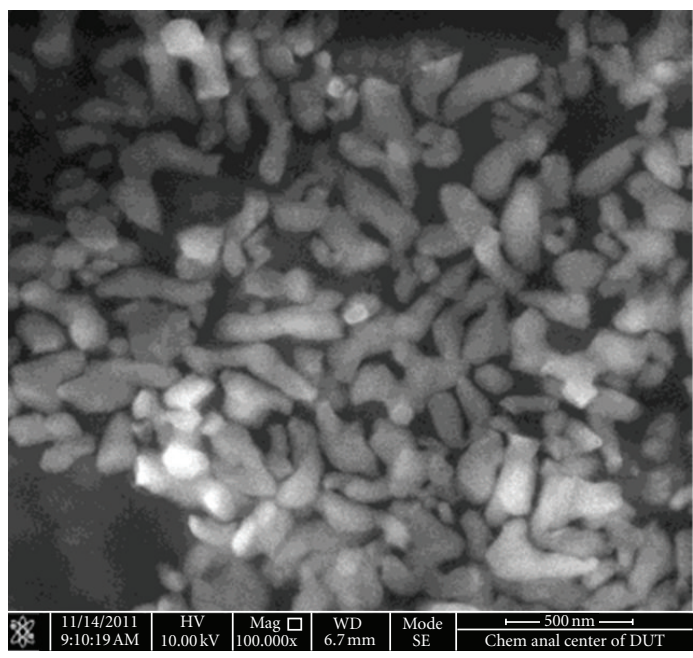

(b)

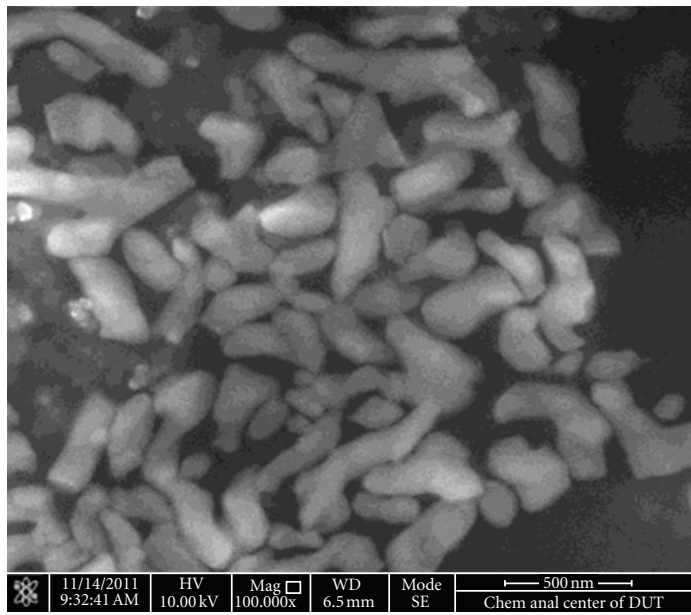

(d)

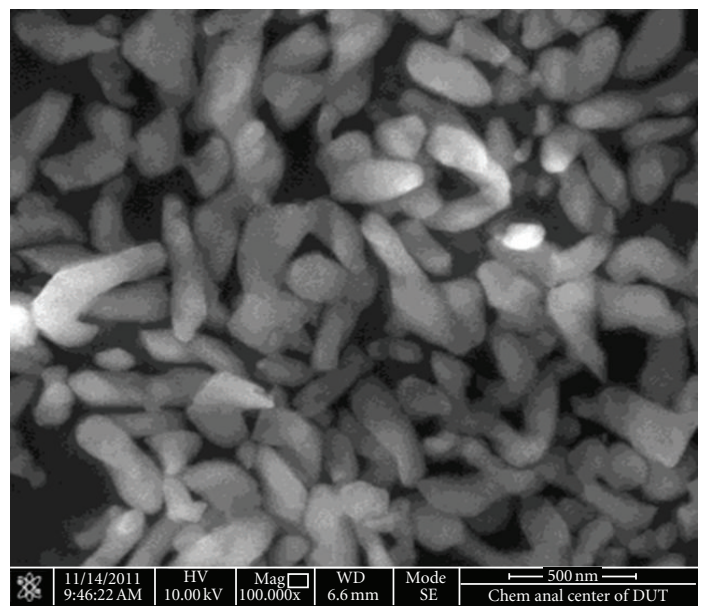

(e)

Figure 6: FE-SEM images of $\mathrm{NaYF}_{4}: \mathrm{Yb}$, Er nanocrystals prepared under different reaction times: (a) $2 \mathrm{~h}$; (b) $4 \mathrm{~h}$; (c) $6 \mathrm{~h}$; (d) $8 \mathrm{~h}$; (e) $10 \mathrm{~h}$ $(\mathrm{RE} / \mathrm{TEPA}=1: 1$; water/ethanol $=1: 1 ; 16.7 \mathrm{mmol} / \mathrm{L})$. 


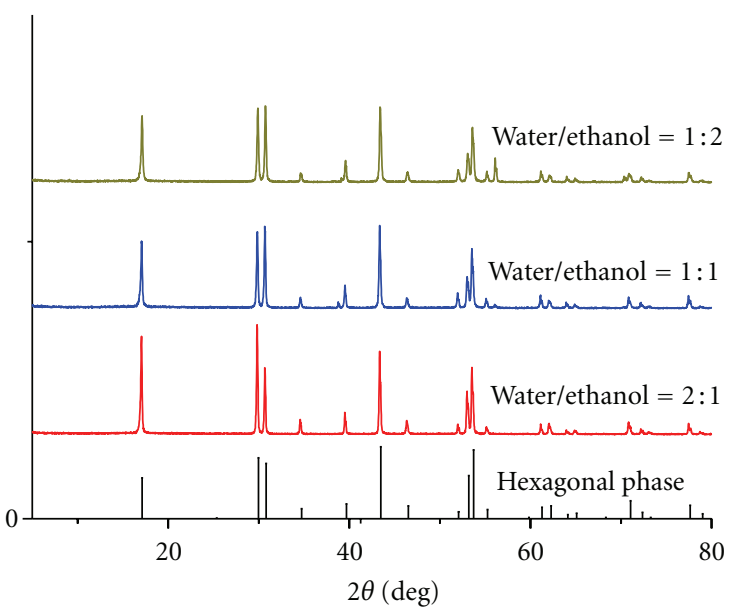

FIGURE 7: XRD patterns of $\mathrm{NaYF}_{4}: \mathrm{Yb}, \mathrm{Er}$ nanocrystals prepared under different solvent composition (RE/TEPA $=1: 1 ; t=6 \mathrm{~h}$; $16.7 \mathrm{mmol} / \mathrm{L})$.

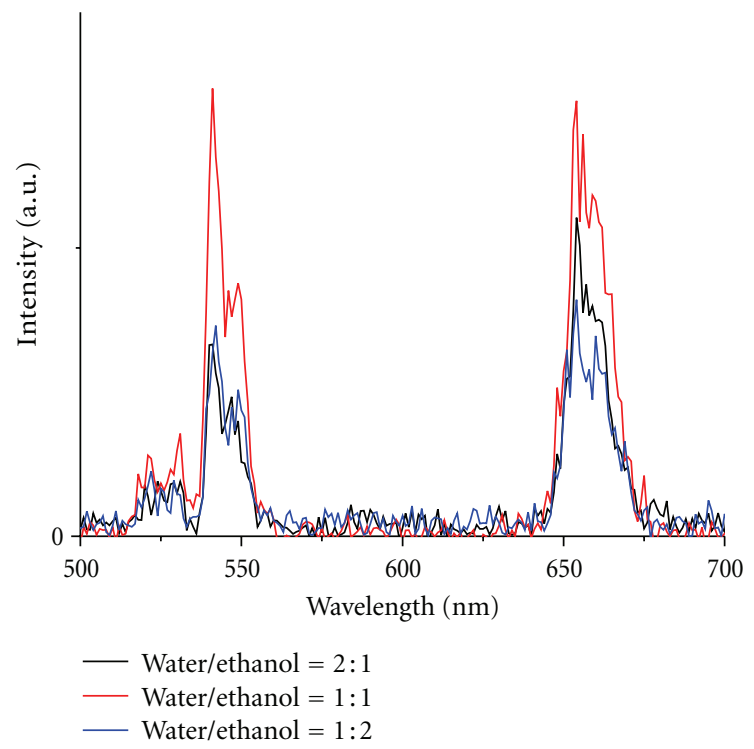

FIGURE 8: Upconverted fluorescence spectra of $\mathrm{NaYF}_{4}: \mathrm{Yb}$, Er nanocrystals prepared under different solvent composition $(\mathrm{RE} / \mathrm{TEPA}=$ $1: 1 ; t=6 \mathrm{~h} ; 16.7 \mathrm{mmol} / \mathrm{L})$.

beneficial to the growth of the nanocrystal, when the time extended to $6 \mathrm{~h}$, prolonged reaction time, nanocrystal's size had no evidence change, but the fluorescence intensity still enhanced. The solvent in different composition of water and ethanol was also discussed; with the increase of ethanol in the solvent, the size of the particle decreases, and when water/ethanol is $1: 1$, the fluorescence intensity of the asprepared samples is strongest. The paper demonstrates that amine can be covered by nanocrystals directly without any other surface modification that makes the synthesis of bioprobe and bioimaging more easy and effective.

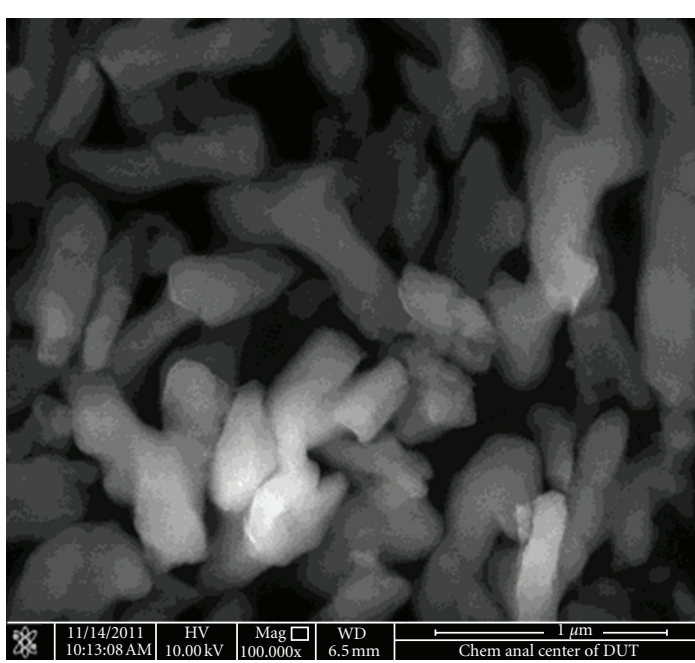

(a)

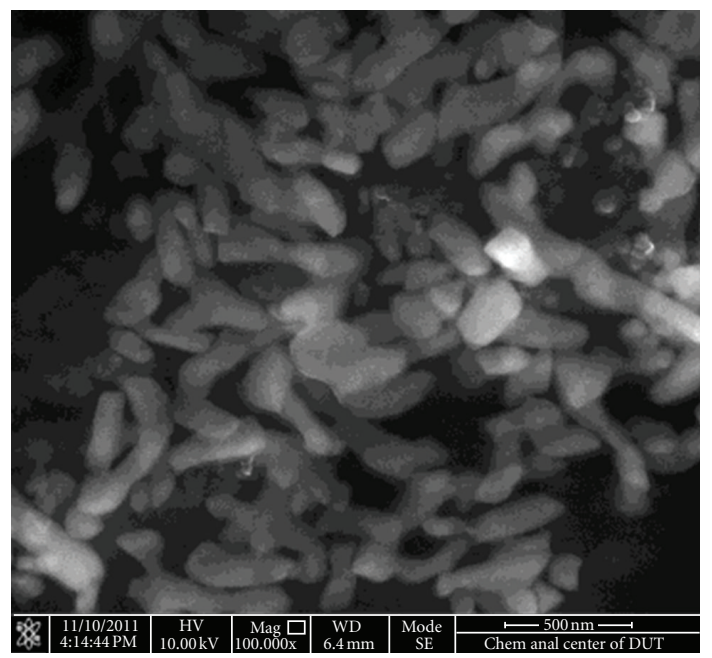

(b)

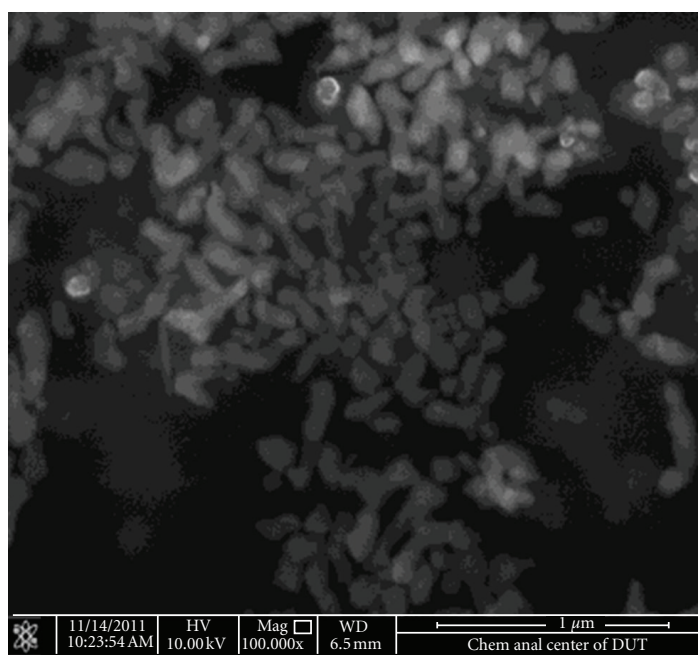

(c)

FIGURE 9: FE-SEM images of $\mathrm{NaYF}_{4}: \mathrm{Yb}$, Er nanocrystals prepared under different solvent composition: (a) water/ethanol $=2: 1$; (b) water/ethanol $=1: 1 ;(\mathrm{c})$ water/ethanol $=1: 2(\mathrm{RE} / \mathrm{TEPA}=1: 1 ; t=$ $6 \mathrm{~h} ; 16.7 \mathrm{mmol} / \mathrm{L})$. 


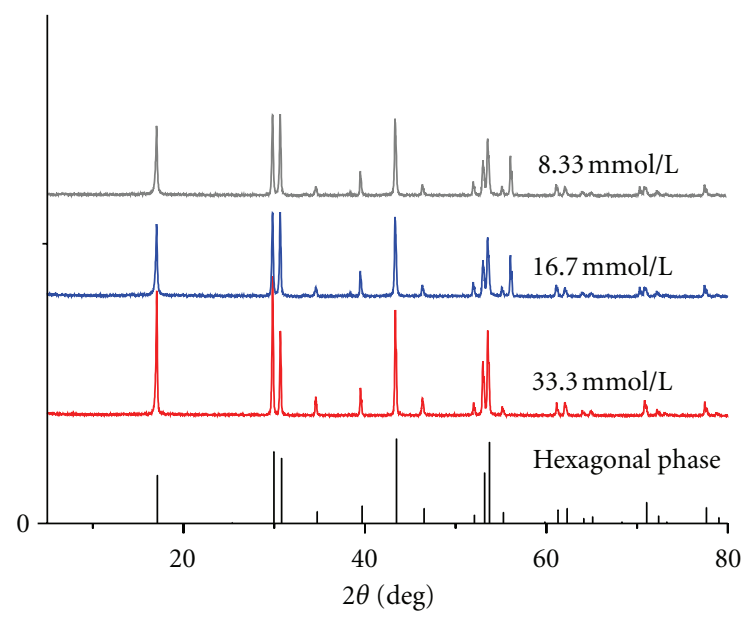

FIGURE 10: XRD patterns of $\mathrm{NaYF}_{4}: \mathrm{Yb}$, Er nanocrystals prepared under different rare earth concentration $(\mathrm{RE} / \mathrm{TEPA}=1: 1 ; t=6 \mathrm{~h}$; water/ethanol $=1: 1$ ).

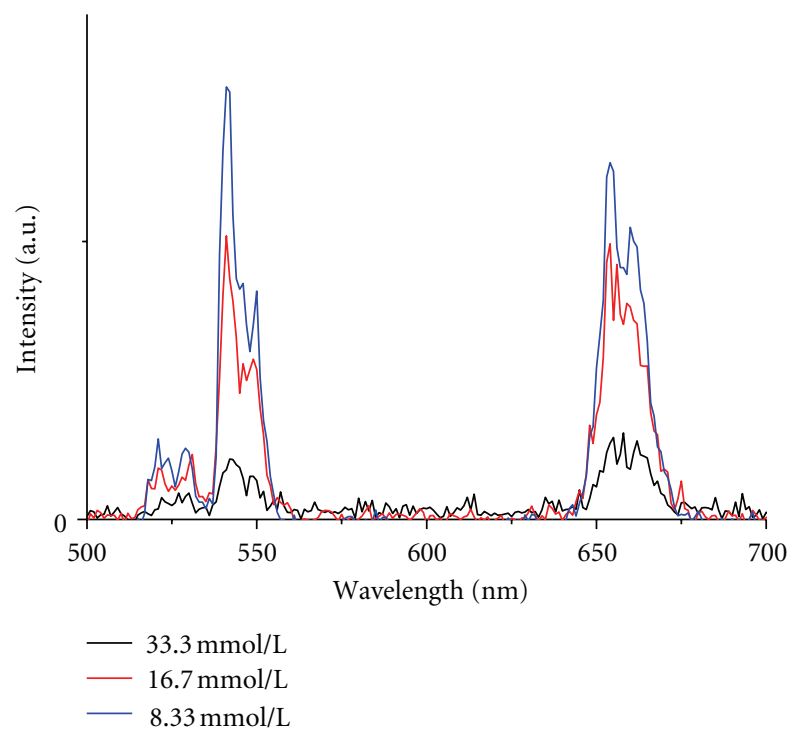

Figure 11: Upconverted fluorescence spectra of $\mathrm{NaYF}_{4}: \mathrm{Yb}, \mathrm{Er}$ prepared under different rare earth concentration $(\mathrm{RE} / \mathrm{TEPA}=1: 1$; $t=6 \mathrm{~h}$; water/ethanol $=1: 1$ ).

\section{Acknowledgments}

This work was supported by the National Natural Science Foundation of China $(21076038,20836001,20923006)$, the Fundamental Research Funds for the Central University (DUT11LK30), National Key Technology Support Program 2011BAE07B01, and the Doctoral Fund of Ministry of Education of China (20100041120024).

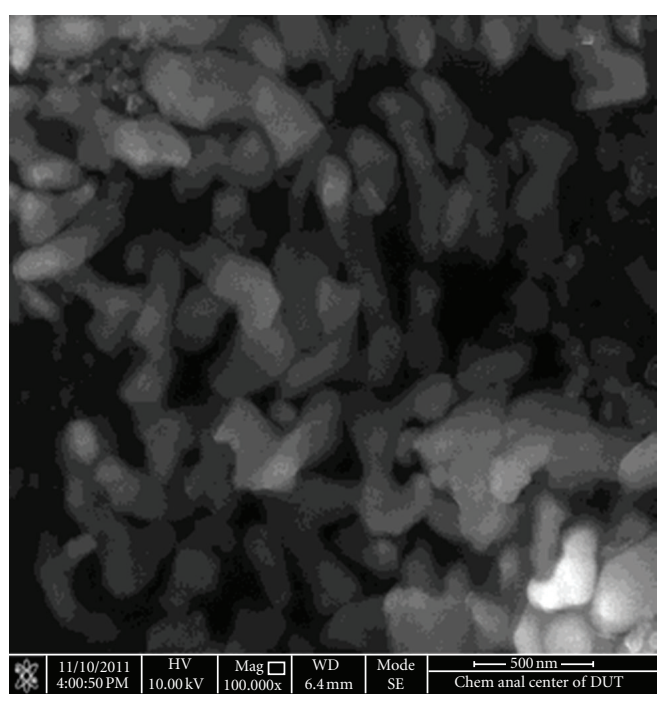

(a)

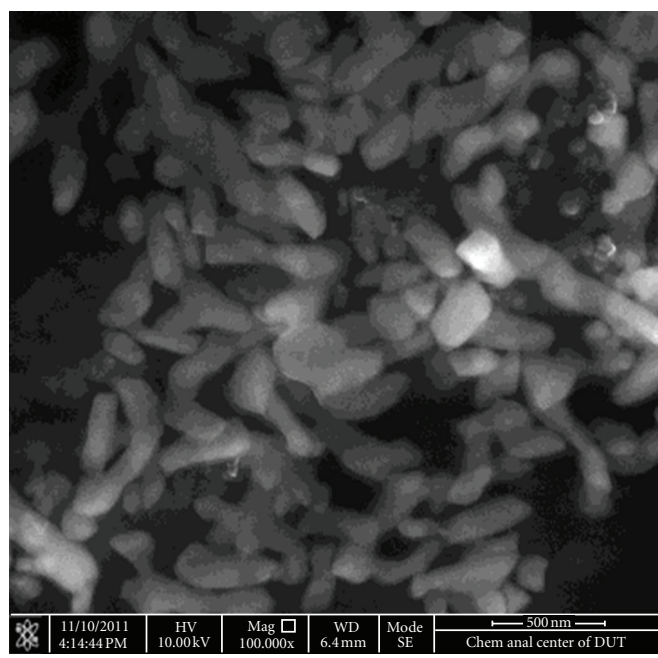

(b)

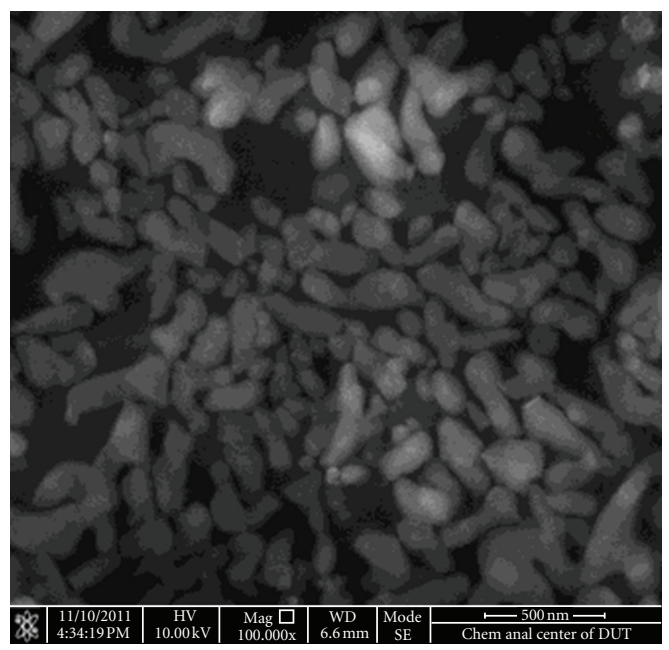

(c)

FIGURE 12: FE-SEM images of $\mathrm{NaYF}_{4}: \mathrm{Yb}$, Er nanocrystals prepared under different rare earth concentration: (a) $8.33 \mathrm{mmol} / \mathrm{L}$; (b) $16.7 \mathrm{mmol} / \mathrm{L}$; (c) $33.3 \mathrm{mmol} / \mathrm{L}$ (RE/TEPA $=1: 1 ; t=6 \mathrm{~h}$; water/ethanol $=1: 1$ ). 


\section{References}

[1] P. L. A. M. Corstjens, S. Li, M. Zuiderwijk et al., "Infrared upconverting phosphors for bioassays," IEE Proceedings Nanobiotechnology, vol. 152, no. 2, pp. 64-72, 2005.

[2] S. F. Lim, R. Riehn, W. S. Ryu et al., "In vivo and scanning electron microscopy imaging of upconverting nanophosphors in Caenorhabditis elegans," Nano Letters, vol. 6, no. 2, pp. 169174, 2006.

[3] G. Yi, H. Lu, S. Zhao et al., "Synthesis, characterization, and biological application of size-controlled nanocrystalline $\mathrm{NaYF}_{4}$ :Yb,Er infrared-to-visible up-conversion phosphors," Nano Letters, vol. 4, no. 11, pp. 2191-2196, 2004.

[4] J. H. Zeng, J. Su, Z. H. Li, R. X. Yan, and Y. D. Li, "Synthesis and upconversion luminescence of hexagonal-phase $\mathrm{NaYF}_{4}: \mathrm{Yb}$, $\mathrm{Er}^{3+}$ phosphors of controlled size and morphology," Advanced Materials, vol. 17, no. 17, pp. 2119-2123, 2005.

[5] K. Deng, T. Gong, L. Hu, X. Wei, Y. Chen, and M. Yin, "Efficient near-infrared quantum cutting in $\mathrm{NaYF}_{4}: \mathrm{Ho}^{3+}, \mathrm{Yb}^{3+}$ for solar photovoltaics," Optics Express, vol. 19, no. 3, pp. 17491754, 2011.

[6] P. Cheben, F. Del Monte, D. J. Worsfold, D. J. Carlsson, C. P. Grover, and J. D. Mackenzie, "A photorefractive organically modified silica glass with high optical gain," Nature, vol. 408, no. 6808, pp. 64-67, 2000.

[7] F. Zhang, Y. Wan, T. Yu et al., "Uniform nanostructured arrays of sodium rare-earth fluorides for highly efficient multicolor upconversion luminescence," Angewandte Chemie, vol. 46, no. 42, pp. 7976-7979, 2007.

[8] Z. Hou, C. Li, P. Ma et al., "Electrospinning preparation and drug-delivery properties of an Up-conversion Luminescent Porous $\mathrm{NaYF}_{4}: \mathrm{Yb}^{3+}, \mathrm{Er}^{3+} @$ silica fiber nanocomposite," Advanced Functional Materials, vol. 21, no. 12, pp. 2356-2365, 2011.

[9] J. Shan, S. J. Budijono, G. Hu et al., "Pegylated composite nanoparticles containing upconverting phosphors and mesotetraphenyl porphine (TPP) for photodynamic therapy," Advanced Functional Materials, vol. 21, no. 13, pp. 2488-2495, 2011.

[10] G. S. Yi and G. M. Chow, "Synthesis of hexagonal-phase $\mathrm{NaYF}_{4}: \mathrm{Yb}, \mathrm{Er}$ and $\mathrm{NaYF}_{4}: \mathrm{Yb}$, Tm nanocrystals with efficient upconversion fluorescence," Advanced Functional Materials, vol. 16, no. 18, pp. 2324-2329, 2006.

[11] W. Niu, S. Wu, S. Zhang, J. Li, and L. Li, "Multicolor output and shape controlled synthesis of lanthanide-ion doped fluorides upconversion nanoparticles," Dalton Transactions, vol. 40, no. 13, pp. 3305-3314, 2011.

[12] W. Niu, S. Wu, and S. Zhang, "A facile and general approach for the multicolor tuning of lanthanide-ion doped $\mathrm{NaYF}_{4}$ upconversion nanoparticles within a fixed composition," Journal of Materials Chemistry, vol. 20, no. 41, pp. 9113-9117, 2010.

[13] J. Shan and Y. Ju, "Controlled synthesis of lanthanide-doped $\mathrm{NaYF}_{4}$ upconversion nanocrystals via ligand induced crystal phase transition and silica coating," Applied Physics Letters, vol. 91, no. 12, Article ID 123103, 2007.

[14] J. Shan, X. Qin, N. Yao, and Y. Ju, "Synthesis of monodisperse hexagonal $\mathrm{NaYF}_{4}: \mathrm{Yb}$, Ln ( $\mathrm{Ln}=\mathrm{Er}$, Ho and $\left.\mathrm{Tm}\right)$ upconversion nanocrystals in TOPO," Nanotechnology, vol. 18, no. 44, Article ID 445607, 2007.

[15] Y. Wang, R. Cai, and Z. Liu, "Controlled synthesis of $\mathrm{NaYF}_{4}$ : $\mathrm{Yb}$, Er nanocrystals with upconversion fluorescence via a facile hydrothermal procedure in aqueous solution," CrystEngComm, vol. 13, no. 6, pp. 1772-1774, 2011.
[16] J. H. Zeng, Z. H. Li, J. Su, L. Wang, R. Yan, and Y. Li, "Synthesis of complex rare earth fluoride nanocrystal phosphors," Nanotechnology, vol. 17, no. 14, article 032, pp. 3549-3555, 2006.

[17] X. Liang, X. Wang, J. Zhuang, Q. Peng, and Y. Li, "Synthesis of $\mathrm{NaYF}_{4}$ nanocrystals with predictable phase and shape," Advanced Functional Materials, vol. 17, no. 15, pp. 2757-2765, 2007.

[18] C. Sun, C. Carpenter, G. Pratx, and L. Xing, "Facile synthesis of amine-functionalized $\mathrm{Eu}^{3+}$-Doped $\mathrm{La}(\mathrm{OH})_{3}$ nanophosphors for bioimaging," Nanoscale Research Letters, vol. 6, no. 1, pp. 24-30, 2010.

[19] P. R. Diamente and C. J. M. Frank, "Water-soluble $\mathrm{Ln}^{3+}$-doped $\mathrm{LaF}_{3}$ nanoparticles: retention of strong luminescence and potential as biolabels," Journal of Fluorescence, vol. 15, no. 4, pp. 543-551, 2005. 

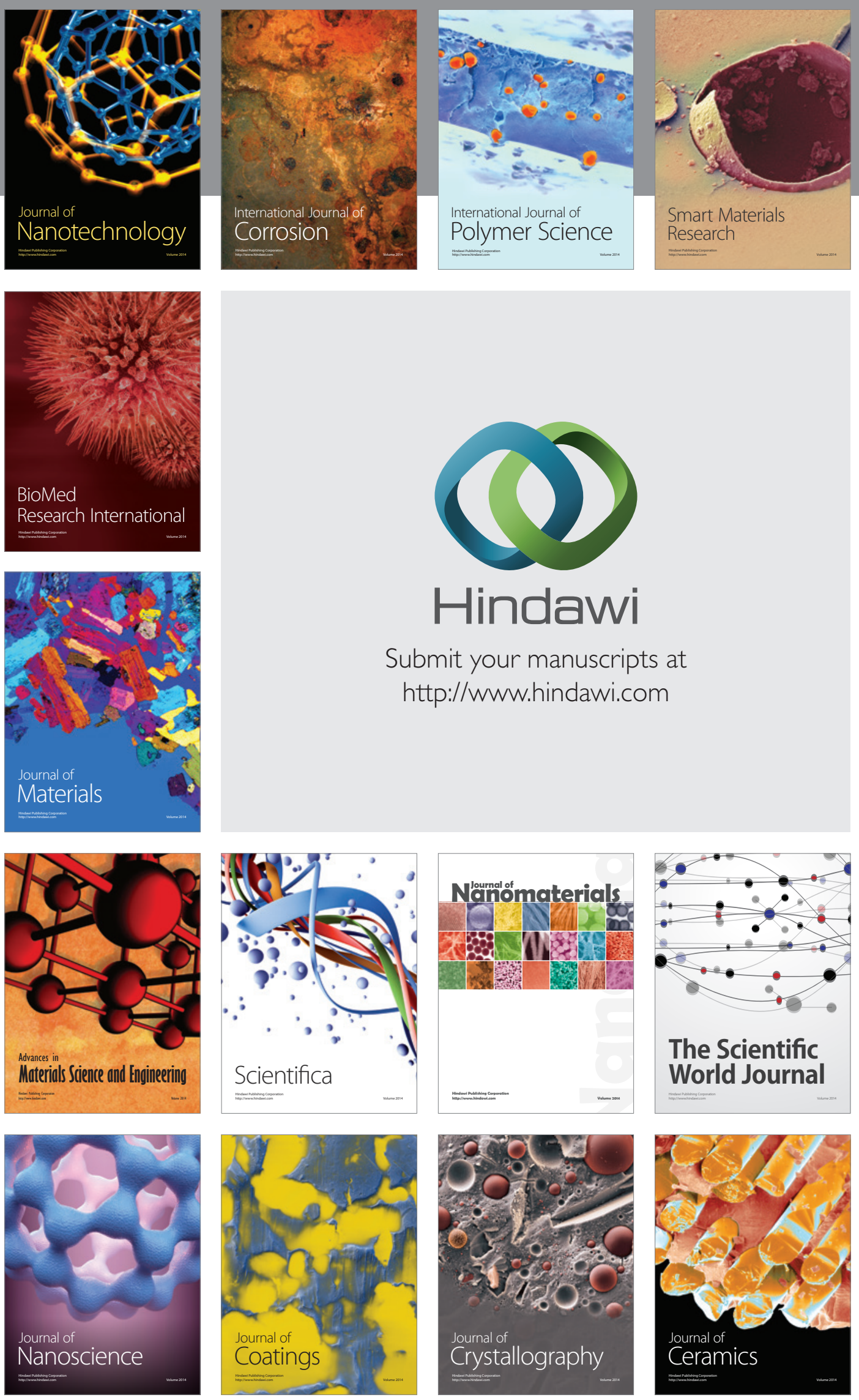

The Scientific World Journal

Submit your manuscripts at

http://www.hindawi.com

\section{World Journal}

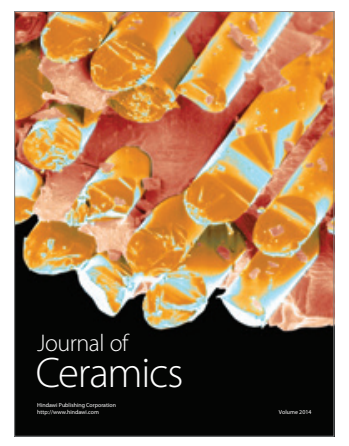

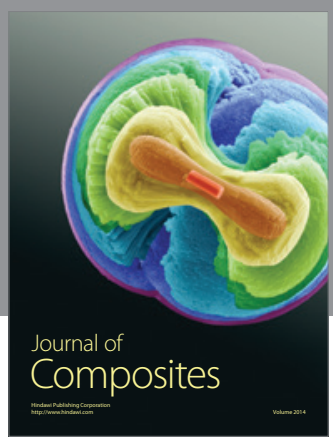
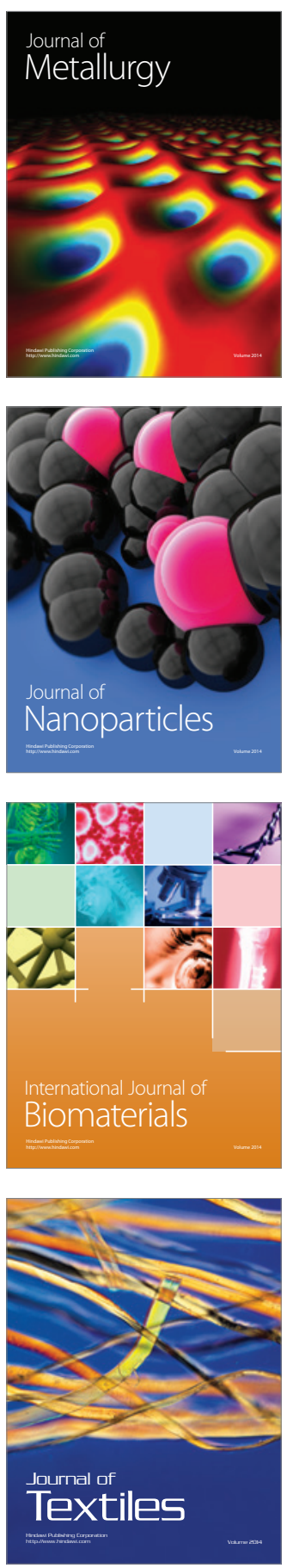